\title{
Diversidad de ESPECIES NATURALIZADAs DEL GÉNERo OPUNTIA (CACTACEAE) utilizadAs POR los POBladores DEL NORTE DE Córdoba (Argentina)
}

\author{
MARÍA LUJÁN AHUMADA y CECILIA TRILLO'
}

\begin{abstract}
Resumen: La agricultura comprendida como el cultivo y la domesticación de plantas constituye una práctica orientada por el conocimiento botánico de las diferentes culturas. El estudio de la diversidad de plantas cultivadas y domesticadas por un pueblo resulta útil para aproximarse a la comprensión de los intereses subyacentes en torno a las mismas. En Argentina, y en particular en Córdoba, son escasos los trabajos etnobotánicos acerca de las relaciones establecidas entre grupos humanos y las cactáceas, por lo cual en este trabajo se realizó una investigación etnobotánica con los pobladores criollos del norte de la provincia. La metodología utilizada consistió en entrevistas abiertas y semiestructuradas, recorridos por el área de estudio y recolección de material de herbario. Se obtuvo como resultado la identificación de siete etnovariedades diferentes denominadas "tunas" actualmente cultivadas y en proceso de domesticación, de las cuales 6 corresponden a la especie botánica Opuntia ficus-indica (4 a la forma ficus-indica: "Amarilla", "Cordobesa", "Italiana" y "Salteña"; y 2 a la forma amyclaea : "Colorada" y "Blanca"), y una a la especie Opuntia robusta ("Cuaresma"). Se registraron los usos de las mismas. A partir de los resultados se registra por primera vez para Córdoba la presencia de O. robusta.
\end{abstract}

Palabras clave: Etnobotánica, Botánica Económica, cactáceas, cultivo y domesticación de plantas

Summary: Diversity of naturalized species of the genus Opuntia (Cactaceae) used by the people of Northern Córdoba (Argentina). Agriculture understood as cultivation and domestication of plants constitute a practice orientated by botanical knowledge of different cultures. The study of plant diversity, cultivated and domesticated by a community is useful for understanding the underlying interests around them. In Argentina, particularly in Córdoba, there are few ethnobotanical research works about the relationship established between human groups and Cactaceae. That is why, in this study, an ethnobotanical research was conducted white creole inhabitants in the north of Córdoba. Methodology consisted of open and semistructured interviews, field exploration and herbarium material collection. We identified seven different kinds of "tunas", which have been collected from natural ecosystem and currently undergo domestication process. Six of them belong to the botanical species Opuntia ficus-indica (4 to form ficus-indica: "Amarilla", "Cordobesa", "Italiana" and "Salteña"; and 2 to form amyclaea: "Colorada" and "Blanca"), and the seventh belongs to the botanical species Opuntia robusta ("Cuaresma"). Plant uses declared during the interviews were recorded, being this the first record of $O$. robusta usage in Córdoba province.

Key words: Ethnobotany, cactaceae, cultivation and domestication of plants. of these plants were recorded.

\section{INTRODUCCIÓN}

En relación al estudio del conocimiento, prácticas y creencias acerca de los vínculos entre los seres humanos y los componentes vegetales de su hábitat se distingue el Conocimiento Botánico

${ }^{1}$ Departamento de Diversidad Biológica y Ecología, Cátedra de Diversidad Vegetal II - Etnobotánica, Universidad Nacional de Córdoba, lujiahumadavalentino@gmail. com, ceciliatrillo1@gmail.com
Tradicional (CBT), el cual orienta y condiciona las estrategias de manejo y manipulación del entorno vegetal, específicamente de las plantas que pueden considerarse como un recurso (Pochettino et al., 2012). Entre las características que lo distinguen se destaca el dinamismo que este conocimiento tiene, ya que se modifica de acuerdo a los ajustes que realiza el grupo humano frente a las circunstancias cambiantes de su ambiente biocultural, dentro del cual estas modificaciones cobran significado. En este contexto, la domesticación, los criterios 
de selección de variedades, la identificación de plantas y las prácticas hortícolas en su conjunto son un ejemplo de las medidas de adaptación a estos cambios (Pochettino et al., 2012; Hurrel, 2014).

Una de las prácticas orientadas por este CBT es la agricultura, que permite la obtención de recursos mediante un proceso productivo en el cual la naturaleza es transformada y la disponibilidad de recursos controlada. En esta práctica se llevan a cabo dos procesos: el cultivo y la domesticación de plantas. El cultivo es el proceso en el cual se manipula el ambiente y se propagan plantas en un medio artificialmente producido, sin la implicancia de cambios en las frecuencias génicas. Sin embargo, debido a su manipulación, el esquema genético de las plantas seleccionadas naturalmente puede cambiar a otro esquema de selección artificial, y es precisamente este proceso de manipulación de genotipos lo que determina la domesticación (Casas et al., 2015).

La domesticación puede ocurrir tanto en plantas silvestres, es decir que crecen espontáneamente fuera de los hábitats controlados por el hombre, así como en plantas que tienen ya un grado avanzado de domesticación, es decir, que dependen del hombre en gran medida para sobrevivir y reproducirse (Casas, 2001; Krapovickas, 2010; Casas et al., 2015).

Dentro de la amplia gama de recursos vegetales que aprovecha el ser humano para distintos fines, se encuentran las "tunas", "pencas" o "cactus", pertenecientes a la familia botánica Cactaceae. Esta es una familia propia a la región Neotropical, constituida por alrededor de 1600 especies (Reyes Agüero et al., 2006), con representantes cultivados en más de 30 países (Rodríguez, 2004). En Argentina se encuentran unos 37 géneros y alrededor de 210 especies, distribuidas en todo el territorio y siendo notables en el Dominio Chaqueño: Provincias Fitogeográficas Chaqueña, Espinal, Prepuna y Monte (Demaio \& Trevisson, 2006; Kiesling et al., 2012). El género Opuntia Mill. pertenece a la subfamilia Opuntioideae y comprende entre 150 a 180 especies reconocidas (Majure et al., 2012). Especies de este género se pueden encontrar creciendo como silvestres, naturalizadas y también cultivadas para el consumo de frutos y cladodios; en todos los casos son habitualmente utilizadas como forraje para el ganado en zonas áridas de Argentina, Brasil,
México, oeste de Asia y norte y sur de África (Reyes Agüero et al., 2006; Karlin et al., 2010; López Gutiérrez et al., 2015). Su centro de origen es México, donde se han encontrado semillas de Opuntia ficus-indica (L). Mill. en depósitos lacustres de 24.000 años de antigüedad, y en nidos fósiles anteriores a 40.000 años (Ortiz \& Van Der Meer, 2007). Este país es el centro más importante de diversidad de cactáceas (Reyes Agüero et al., 2006), donde según estos autores, partes del paisaje están conformadas por "nopaleras", asociaciones de diversas plantas denominadas de esta manera debido a la dominancia estructural y/o fisonómica de varias especies de Opuntia sensu stricto, denominadas localmente "nopales".

La especie de cactácea de mayor importancia económica en el mundo es Opuntia ficus-indica, denominada por los pobladores con los nombres de "tuna", "nopal" y "chumbera" (Kiesling, 1998; Hernández et al., 2005). Esta especie ya en el siglo XVI era conocida en Europa, y posiblemente fue llevada allí en el primer o segundo viaje de Colón a América, aunque el primer registro para México es en 1515 (según la crónica de Fernández de Oviedo de 1535, reproducida en López Piñero et al., 1992), donde se afirmaba que sus cladodios era utilizados como provisiones para los viajes por mar, para combatir el escorbuto, siendo introducida de esta manera por las distintas partes del mundo (Kiesling, 1998; Pimienta Barrios et al., 2003; Griffith, 2004). Griffith (2004) pudo constatar a través de análisis de AFLP (polimorfismos de longitud de fragmentos amplificados) que O. ficus indica ha sido domesticada a partir del cultivo en el centro de México, desde donde se extendió posiblemente través del comercio entre los pueblos de Mesoamérica. Debido a su domesticación, esta especie atravesó procesos de gran manipulación genética desde la época prehispánica, que se dirigió principalmente en la obtención de variedades fáciles de cosechar -esto es, sin espinas o escasas, más vigorosas, frutos grandes con mejor sabor. Esta domesticación en los huertos y la retrocruza con plantas silvestres, ha dado lugar a un intenso flujo génico por la cual surgió una gran diversificación infraespecífica (Kiesling, 1998; Griffith, 2004). Así mismo, Bellón et al. (2009) mencionan que en México son utilizadas más de 20 especies del género Opuntia, entre estas últimas una de las principales plantas útiles prehispánicas 


\section{L. Ahumada y C. Trillo - Diversidad del género Opuntia en el norte de Córdoba}

debido a sus frutos comestibles y con mayores manipulaciones actuales es Opuntia robusta J.C. Wendl., cultivada principalmente como forraje y con fines ornamentales (Ramírez et al., 2000).

Para Córdoba, Torrico Chalabe \& Trillo (2015) destacan, en el marco de un estudio etnobotánico realizado en el norte de la provincia, que $O$. ficus indica presenta el mayor número de menciones y diferentes tipos de usos, evidenciando su relevancia como recurso natural. Ya a principios del siglo pasado es mencionada por Río \& Achával (1905), con distribución en el norte y oeste de la provincia, donde cobra un gran interés forrajero debido a la escasa fertilidad de los terrenos, recomendando su cultivo por el bajo costo que requiere, por la abundancia del producto y por la ventaja de que los cultivares pueden conservarse durante muchos años. También es apreciada por sus sabrosos frutos $\mathrm{y}$ por sus tallos, que son un recurso maderero, forrajero, comestible y medicinal (Zapata et al., 2005; Trillo et al., 2010).

En Argentina existen publicaciones de referencias etnobotánicas que documentan el uso de esta especie, pero en marcos de estudios más amplios, tales como el estudio de Biurrun et al. (2007) en la Rioja con plantas alimenticias o el trabajo realizado por Scarpa (2012) con los criollos del oeste de Formosa en la subsistencia de su vida ganadera. Particularmente para la provincia de Córdoba, son escasos los estudios etnobotánicos sobre esta especie de suma importancia económica y cultural, por lo cual este trabajo representa un enriquecedor aporte para profundizar sobre el valor cultural de este recurso vegetal.

Ante la escasez de trabajos etnobotánicos enfocados en cactáceas en Córdoba, y la importancia que este recurso posee, este trabajo pretende identificar la diversidad de especies de Opuntia cultivadas por los pobladores del norte de la provincia de Córdoba, describir los usos locales de estas plantas y analizar los resultados desde una perspectiva etnobotánica.

\section{Materiales y Métodos}

\section{Área de estudio}

El área de estudio se ubica al norte de la Provincia de Córdoba, en los departamentos de Río Seco, Tulumba e Ischilín, pertenecientes desde el punto de vista fitogeográfico a la Provincia Chaqueña (Cabrera, 1976). Estos departamentos se encuentran ubicados en las planicies del Distrito Chaqueño Occidental, las serranías del Distrito Chaqueño Serrano y en las depresiones ubicadas en el sector de las Salinas Grandes (Cabrera, 1976; Cabido \& Zak, 1999). Estos últimos autores dividen el norte cordobés según la diversidad de formas de relieve que se resumen en las siguientes unidades geomorfológicas: Salinas Grandes, Planicie Occidental, Sistema Serrano, Planicie Oriental y Depresión de Mar Chiquita (Figura 1), conformando así 5 unidades fisiográficas, y en 2 sectores según el clima: Occidental y Oriental (Cabido \& Zak, 1999).

El presente estudio se llevó acabo en las Salinas Grandes, Planicie Occidental, y en la transición entre la Planicie Oriental y Sistema Serrano (Figura 1).

De la Planicie Occidental se visitaron dos localidades: Chuña y Quilino; en el sector de las Salinas Grandes: Lucio V. Mansilla y San José de las Salinas; y en la transición entre la unidad Serrana y la Planicie oriental se visitaron: Cerro Colorado, Rayo Cortado, Santa Elena, Villa María de Rio Seco y San José de la Dormida (Figura 1).

\section{Contexto sociocultural}

Desde el punto de vista productivo y socioeconómico, los departamentos del norte de la provincia de Córdoba comprenden la región extra-pampeana de la República Argentina, caracterizada por un menor desarrollo capitalista relativo en relación al área pampeana (Manzanal \& Rofman, 1989). Sin embargo, estas áreas marginales han atravesado durante las últimas dos décadas un incremento en la superficie cultivada, en un principio por el aumento de los cultivos de forrajeras y posteriormente por la expansión del área destinada al cultivo de soja (Cabido et al., 2005). De esta manera, los sistemas de producción actuales no consisten sólo en la cría de vacunos y caprinos, y en la explotación forestal (Trillo 2010; Torrico Chalabe \& Trillo, 2015), sino que engloban la conversión de bosques en tierras para cultivos de granos y la implantación de forrajeras destinadas a la ganadería (Cabido et al., 2005). Los pobladores entrevistados en este trabajo se autodenominan "criollos", tal como lo registran Trillo et al. (2014) y Torrico Chalabe \& Trillo (2015), y forman parte de las sociedades campesinas del norte de 


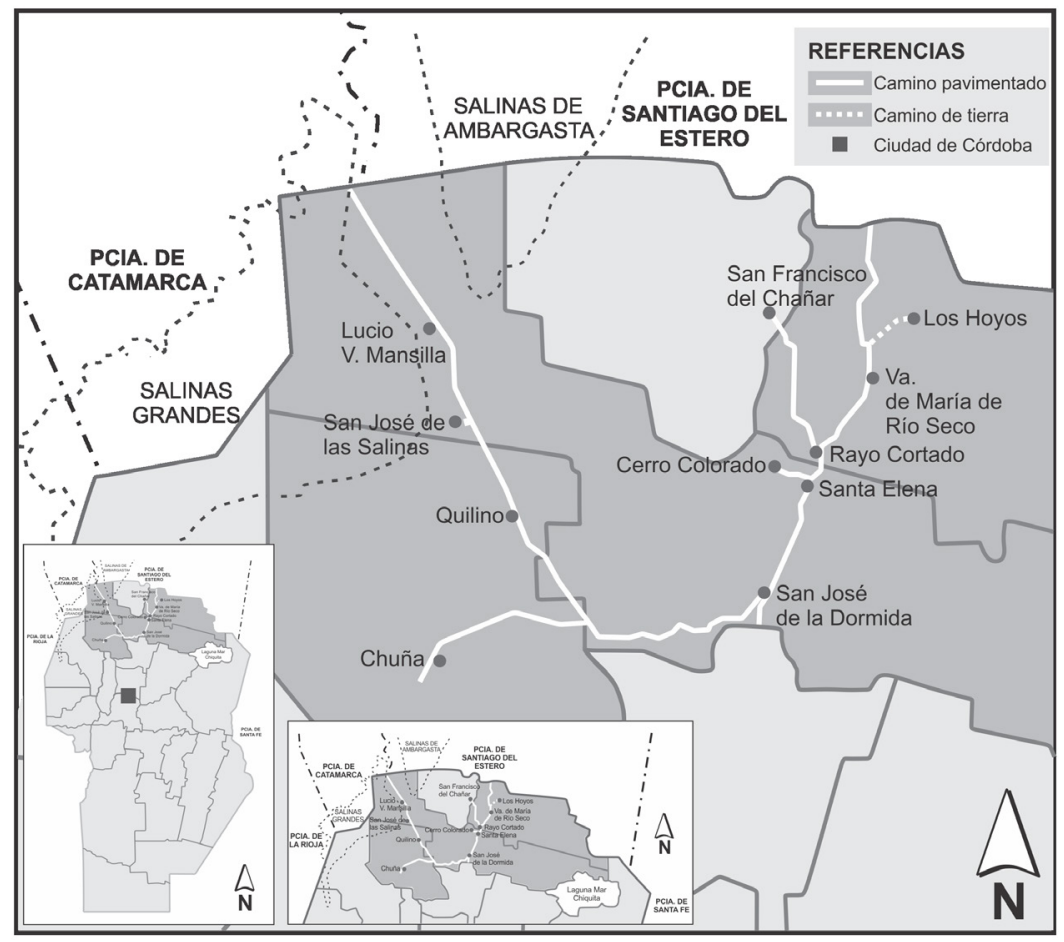

Fig. 1. Área de estudio y ubicación de los sitios visitados. Cerro Colorado, Rayo Cortado, Santa Elena, Villa de María de Río Seco, San José de la Dormida, Los Hoyos (Transición entre la unidad Serrana y la Planicie Oriental), Chuña, Quilino (Planicie Occidental), Lucio V. Mansilla y San José de las Salinas (Salinas Grandes).

la provincia de Córdoba, realizando actividades económicas orientadas a la venta de productos artesanales y turismo, así como una pequeña producción ganadera destinada al autoconsumo y ventas menores (Torrico Chalabe \& Trillo, 2015).

\section{Metodología}

Inicialmente se realizó observación participante (Padua, 1994) y se llevaron a cabo unas primeras visitas con entrevistas abiertas y caminatas por los espacios domésticos y naturales ("el monte"), con preguntas generales (Cotton, 1996) acerca del uso de especies de "tunas" que conocen.

Posteriormente se llevaron a cabo entrevistas semi-estructuradas aplicando metodología ad hoc (Padua, 1994; Bernard, 1994; Cotton, 1996; Aldrige \& Lavine, 2003). Las entrevistas constaron de preguntas relativas a la identificación de la diversidad de "tunas", a la nomenclatura y a los usos locales. Las mismas fueron acompañadas por un muestrario fotográfico a partir de las especies del género Opuntia identificadas por los pobladores.

Se realizó una muestra no aleatoria, denominada "bola de nieve" (Aguilera et al., 2003), de esta manera sólo se incluyeron informantes clave, el cual es un especialista o experto nativo que tiene un profundo conocimiento de un aspecto particular de la cultura local (Costa-Neto, 2002) en este caso de "tunas".

Se trabajó con un total de 24 personas (17 mujeres y 7 varones), con una edad promedio de 57 años (40 mín. y 88 máx.). Con cada uno de los informantes se realizó una caminata en la zona doméstica y peridoméstica, con la intención de corroborar las especies de Opuntia naturalizadas nombradas por los mismos.

En este trabajo se utilizará la denominación de etnovariedad, término que según Perales et al. (2003) y Obón \& Rivera (2005), es aquella diversidad infraespecífica generada a partir de 


\section{L. Ahumada y C. Trillo - Diversidad del género Opuntia en el norte de Córdoba}

procesos de selección natural y artificial, adaptadas al manejo y a las características locales, las cuales quedan definidas por un contexto cultural concreto, tradicional, y son caracterizadas por un atributo o conjunto de atributos, en virtud de lo cual resultan claramente diferenciable, uniforme y estable. Las etnovariedades son funcionales a las preferencias de uso y elección local y se clasifican en base a sistemas biológicos "folk" (Berlin, 1992), es decir sistemas construidos a partir de los conocimientos y prácticas que posee un pueblo.

Se recolectaron muestras de cada etnovariedada los fines de confeccionar un herbario de referencia, depositado en el Museo Botánico de la Universidad Nacional de Córdoba (CORD). La diversidad de especies, formas y etnovariedades de Opuntia naturalizadas relevadas, fueron registradas además de manera fotográfica. La identificación de las mismas se realizó con la utilización de guías de campo (Kiesling \& Ferrari, 2005; Demaio \& Trevisson, 2006) y con consultas a profesionales y consultando la base de datos del Instituto de Botánica Darwinion (www.darwin.edu.ar) y de la página del Missouri Botanical Garden en (www.tropicos.org).

\section{Análisis de los datos y procedimiento estadístico}

Se confeccionó una tabla con el listado de especies tratadas, con su respectivo nombre científico, los nombres vernáculos y los usos nombrados y descriptos por los informantes (Tabla 1).

Se calculó la frecuencia relativa de citas de cada etnovariedad (FRC), que se obtiene dividiendo el número de informantes que mencionan la etnovariedad por el número de informantes que participan del muestreo (Aguirre-Deguá et al., 2012) y se representó en un histograma de frecuencias relativas. Este índice nos permite establecer la relevancia que tiene para los entrevistados cada una de las etnovariedades, lo que se puede traducir como el grado de conocimiento y difusión de las prácticas en torno a las mismas (Lambaré, 2016).

Para la definición de los usos se tomó la clasificación de 24 usos de Braier que se utilizan en Secretaría de Ambiente y Desarrollo Sustentable (SAyDS), en la Secretaría de Agricultura, Ganadería, Pesca y Alimento (SAGPyA) ambas de carácter nacional y en la Organización de las Naciones Unidas para la Alimentación y la Agricultura FAO (Morello et al., 2009). Los usos fueron agrupados en 10 categorías diferentes y se confeccionó un histograma de frecuencias absolutas reflejando el porcentaje de uso para cada taxón por categoría uso.

\section{Resultados}

\section{Taxones identificados}

Los pobladores del norte de la provincia de Córdoba, designan con el nombre "tuna" a un conjunto de especies relacionadas entre sí taxonómicamente. A partir de las entrevistas realizadas y el reconocimiento botánico de los jardines y huertas se identificaron los siguientes taxones:

Opuntia ficus-indica (L.) Mill. f. ficus-indica (Fig. 2. A, B)

Plantas arbustivas o arbóreas, hasta de $5 \mathrm{~m}$ al. Tronco leñoso bien definido, artejos oblongos a espatulados, de 30-50 cm long., 20-30 cm lat. y ca. $2 \mathrm{~cm}$ espesor, de color verde opaco, algo grisáceo por la capa de cera que los cubren, con areolas muy separadas: $2-5 \mathrm{~cm}$. Espinas generalmente ausentes o hasta 2 por areola, cortas: solo $0,51 \mathrm{~cm}$, débiles, blancuzcas. Flores de 6-8 cm long. x 7-10 cm diám., amarillas, pocas veces anaranjadas. Frutos ca. 6 (-8) cm long. y $3(-4) \mathrm{cm}$ diám., con numerosas areolas, tuberculados, ovales, amarillentos, rojizos o anaranjados. El peso de los frutos varía en las variedades hortícolas entre menos de 100 hasta casi 250 gr (Kiesling, 1998).

Es posible distinguir fácilmente $O$. ficus-indica de las otras especies sudamericanas ya que el receptáculo floral y los frutos presentan numerosas areolas (38 o más, raro menos en algunos cultivares), dispuestas sobre tubérculos notables. Las especies nativas de Sudamérica, en cambio, presentan pocas areolas en las flores y frutos, y no dispuestas sobre tubérculos (Kiesling, 1998). Existen numerosas descripciones completas de esta tan conocida especie (p. ej. Britton \& Rose, 1919; Bravo \& Sánchez Mejorada, 1978).

$O$. ficus indica es una especie tropical o subtropical originaria de México y Centroamérica que se ha expandido a países de África, Asia, Europa y Oceanía, en donde se la cultiva (Falasca et al., 2011). Presenta una gran diversidad de colores en el futo, de acuerdo a su etapa de maduración, encontrándose de color verde claro, 
Bol. Soc. Argent. Bot. 52 (1) 2017
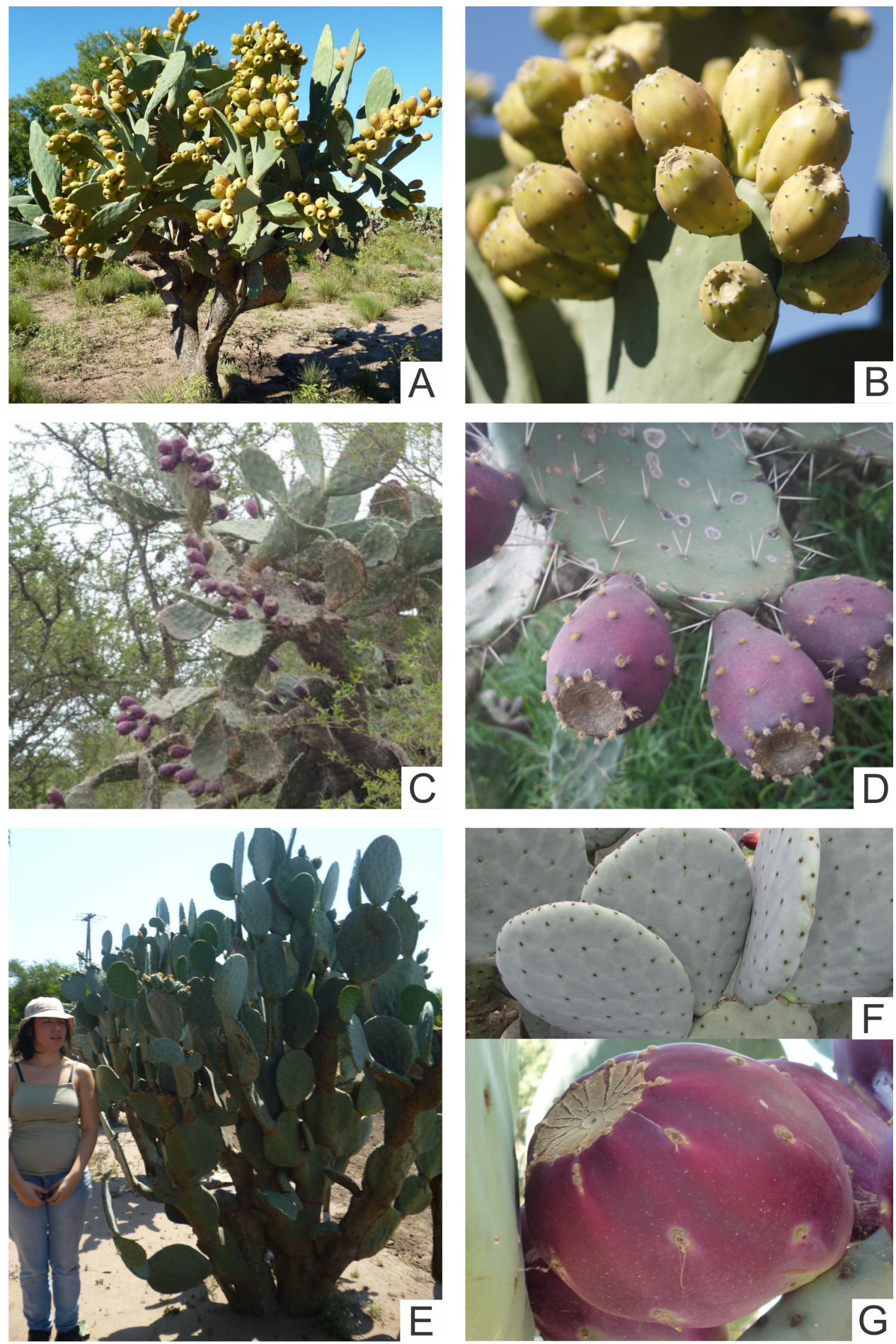

Fig. 2. Taxones identificados en el norte de Córdoba designados con el nombre "tuna". A-B: planta entera, detalle de artejo y fruto de O. ficus-indica f. ficus-indica. C-D: planta entera, detalle de artejo y fruto de $O$. ficus-indica f. amyclaea. E-F-G: planta entera, detalle de artejo y fruto de O. robusta. 


\section{L. Ahumada y C. Trillo - Diversidad del género Opuntia en el norte de Córdoba}

amarillo, anaranjado y rojizos (Hernández et al., 2005). La mayor parte de las etnovariedades registradas pertenecen a esta forma, encontrándose las etnovariedades "Amarilla", "Anaranjada Cordobesa", "Anaranjada Italiana" y "Salteña”.

\section{Opuntia ficus-indica (L.) Mill. f. amyclaea (Ten.) Schelle (Fig. 2. C, D)}

Plantas hasta $5 \mathrm{~m}$ al., muy ramificadas. Artejos ovales, grandes: aproximadamente de $30 \mathrm{~cm}$ long., $20 \mathrm{~cm}$ lat. y $2 \mathrm{~cm}$ espesor, con numerosas areolas, separadas ca. $2 \mathrm{~cm}$, con tomento castaño oscuro, de ca. $4 \mathrm{~mm}$ diám., sobresalientes. Espinas pocas en artejos jóvenes, luego ca. 10, hasta de 2,5 cm long., irregulares, flexibles, blancas, la mayoría reflexas. Flores grandes, amarillas. Frutos obcónicos, desde globosos, pequeños: ca. $3,5 \mathrm{~cm}$ long. y $3 \mathrm{~cm}$ diám., hasta bastante grandes, alargados, en forma de barril: 5 (-7) cm long. y $3(-5) \mathrm{cm}$ diám., con numerosas (ca. 30-40) areolas prominentes, sin espinas o pocas y pequeñas (Kiesling, 1998).

Se la encuentra frecuentemente en Salta, La Rioja, Catamarca, Córdoba y en otras provincias del país. Muchas veces se la observa cultivadas por sus frutos o también asilvestrada (Kiesling, 1998), pero siempre cerca de caminos o poblaciones. En el Perú se cultiva profusamente -más que la forma típica- ya que por poseer espinas no es comida por los animales domésticos. Se la utiliza con doble propósito: para la cría de la cochinilla de la grana (Dactylopius sp.) con fines tintóreos y por sus frutos. Las etnovariedades registradas pertenecientes a esta forma son la "Colorada" y la "Blanca".

\section{Opuntia robusta J.C. Wendl. (Fig. 2. E, F, G)}

Planta arbustiva, muy ramificada, de 1 a $2 \mathrm{~m}$ de al; su tronco está más o menos definido, con ramas de $1.5 \mathrm{~m}$ de largo y cladodios orbiculares o algo oblongos, de 15 a $40 \mathrm{~cm}$ de longitud o más, muy robustos, de color azulado los medios, los jóvenes terminales verde - azulados. Areolas grandes, espaciadas de 3,5-4.5 cm en los artículos medios, en los jóvenes espaciadas de 1,5-2cm con gloquidios de color café. Espinas en número de 3 -5 , de $0,5-2,5 \mathrm{~cm}$ de longitud, blancas o blanco - amarillentas, de tamaño desigual, en los artículos jóvenes ausentes excepto en la zona marginal
(Muñoz Urias et al., 2008). Las flores de $5-6 \mathrm{~cm}$ de diámetro, de color amarillo. Tépalos obovados de $3-3,5$ x $1-1,5 \mathrm{~cm}$ de anchura. Lóbulos estigmáticos de color verde. El fruto globoso o elíptico, purpúreo (Ortiz \& Van Der Meer, 2007). Cultivada mayormente como forrajera, aunque también son muy apetecidos sus frutos, globosos y rojos (Kiesling, 1998).

Es originaria del centro de México (Baker et al., 2008), y en nuestro país sólo hay registro para la provincia de Salta (Kiesling et al., 2012). La etnovariedad registrada perteneciente a esta especie es llamada "Cuaresma".

Se generó un herbario de referencia con 6 ejemplares pertenecientes a las etnovariedades "Amarilla Común", "Anaranjada Cordobesa" y "Anaranjada Italiana" correspondientes a la f. ficus-indica, "Cuaresma" correspondiente a O. robusta y "Colorada" correspondiente a f. amyclaea. Estos dos últimos taxones resultan de sumo interés, ya que no se encuentran en la colección del Museo Botánico dependiente de la Universidad Nacional de Córdoba, por lo que representa un enriquecimiento de la diversidad botánica del mismo.

\section{Relevancia de las etnovariedades}

Con respecto a los índices de frecuencia relativa de las especies (Fig. 3), se observa que la etnovariedad "Amarilla" es la que presenta mayor $\mathrm{FRC}=1$, es decir que esta etnovariedad fue mencionada por la totalidad de los entrevistados, lo cual se relaciona estrechamente con el número de usos y menciones de usos para la misma (Fig. 4) La etnovariedad "Colorada" presenta una relevancia de 0,87 , el cual también se refleja en el número de usos y el número de citas de usos. Luego, la etnovariedad "Anaranjada Cordobesa" posee una $\mathrm{FRC}=0,66$. Este valor es alto si se tiene en cuenta que su fruto es considerado desabrido, por lo cual no es preferida para consumo fresco, sino para la preparación de arropes debido a su gran productividad. Dos etnovariedades presentan la misma FRC $=0,33$, la "Blanca" y "Cuaresma", la primera es utilizada como alimento, aunque se consume y recolecta en el monte, siendo sólo en dos casos registrado que se cultivaron en jardines, mientras que la "Cuaresma" es utilizada principalmente como forraje y ornamental, con escaso uso alimenticio debido al sabor ácido de sus 
frutos. Por último la etnovariedad "Salteña" es la que presenta menor $\mathrm{FRC}=0,12$. Esta etnovariedad fue registrada en sólo 3 casos, y sólo en 2 se mencionó poseerla.

\section{Usos tradicionales}

Se registraron 26 usos, los cuales fueron agrupados en 10 categorías de uso ad-hoc diferentes: alimenticio, cosmético, ornamental, forraje, limpieza, apicultura, construcción de cerco, elaboración de alcohol, tintes y comercialización. (Tabla 1)

\section{1- Alimenticio}

La categoría de uso alimenticio presenta el mayor número de menciones totales (88) para las diferentes variantes de uso. Entre ellos, el más mencionado es la preparación de arrope, con 41 menciones si se considera las 4 variantes que este posee. Estos diferentes tipos de arrope se consiguen según la presencia o no de la pulpa y del tiempo de cocción. Es interesante destacar que la etnovariedad "Amarilla" es utilizada de todas las maneras registradas siendo además la que mayor menciones posee (44).

\section{2- Alcohol}

Se mencionó en 1 sólo caso la preparación de alcohol con los frutos de la etnovariedad "Amarilla".

\section{3- Cosmético}

Para la categoría de uso cosmético se obtuvieron 2 menciones en total, sólo un informante comentó la preparación de crema y shampoo con la etnovariedad "Amarilla".

\section{4- Apicultura}

La categoría de uso apicultura se refiere al uso intencional de las plantas como fuente de néctar y polen para la cría de colmenas. Un informante mencionó haber tenido colmenas en su espacio peridoméstico, utilizando a las etnovariedades "Amarilla" y "Blanca".

\section{5- Ornamental}

La categoría de uso ornamental recibió 2 menciones en total, y se refiere a que la planta es utilizada en la fachada delantera de la casa, en la vereda o en el jardín, sin que sus frutos sean consumidos como alimento, pero sí en algunos casos como forraje. Este es el caso de la etnovariedad "Cuaresma", donde además su presencia se asocia con el prestigio decorativo del hogar, "es una planta de lujo".

\section{6- Tinte}

Para la categoría de uso tinte se presentan 2 menciones en total, una de ellas es para la etnovariedad "Cuaresma", donde un entrevistado mencionó que es "buena para teñir por el color remolach a de sus frutos", y otro entrevistado destaca que la etnovariedad "Anaranjada Cordobesa" tiñe la bolsa en la que se recogen los frutos.

\section{7- Comercialización}

La categoría de uso comercialización, se refiere a la venta de productos realizados a partir de los frutos y es una de las categoría con mayor número de menciones (9), además del uso como alimento y forraje. Se vende principalmente arrope, con todas sus variantes mencionadas. La etnovariedad que más se utiliza para ello es la "Amarilla": " $L a$ más rica, la más dulce de todas es la Amarilla, la común". Le siguen las Anaranjadas, elegidas por la gran productividad que tienen pero no por su sabor, y la etnovariedad "Colorada". Las otras etnovariedades también se utilizan para hacer arrope, pero no para venderlo. En ese caso son para consumo familiar o regalo. La venta se realiza en los hogares o puestos en la ruta. Un entrevistado mencionó que su hijo transporta frutos de la etnovariedad "Amarilla" desde Villa de María de Río Seco hacia la Ciudad de Córdoba durante la época de fructificación a su verdulería.

\section{8- Limpieza}

La categoría de uso limpieza alude a la utilización del mucílago de los artejos como floculante del agua. Para ello es cortado un artejo por la mitad e introducido al recipiente con agua que se desea limpiar, de esta manera el mucílago aglutina las partículas en suspensión y las decanta.

\section{9- Cerco}

La categoría de uso cerco se refiere a la utilización de los individuos como barrera de un cultivo de la etnovariedad "Amarilla". Este caso fue registrado para la etnovariedad "Colorada", y es debido a la presencia de espinas de la misma.

\section{0- Forraje}

La categoría de uso forraje es la segunda categoría con el mayor número de menciones (48), e involucra el consumo por el ganado tanto de la raíz, fruto y tallo, y la preparación de mermelada para cabras mencionada en un caso por un entrevistado. Es interesante destacar que el conjunto de estas etnovariedades fructifican en diferentes momentos, ofreciendo 5 meses disponibles de alimento con 
M. L. Ahumada y C. Trillo - Diversidad del género Opuntia en el norte de Córdoba

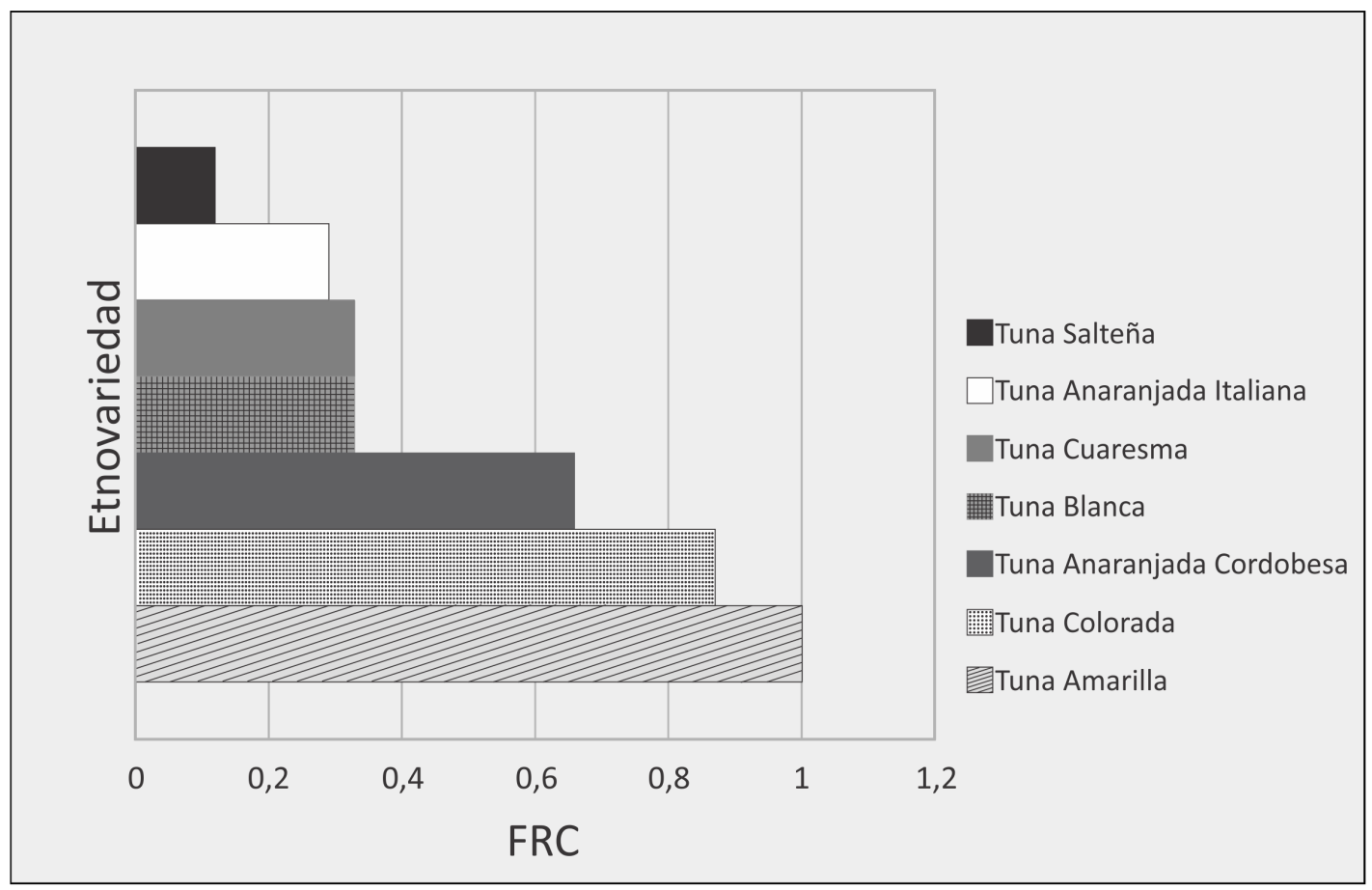

Fig.3. Frecuencias relativas de citas de cada etnovariedad.

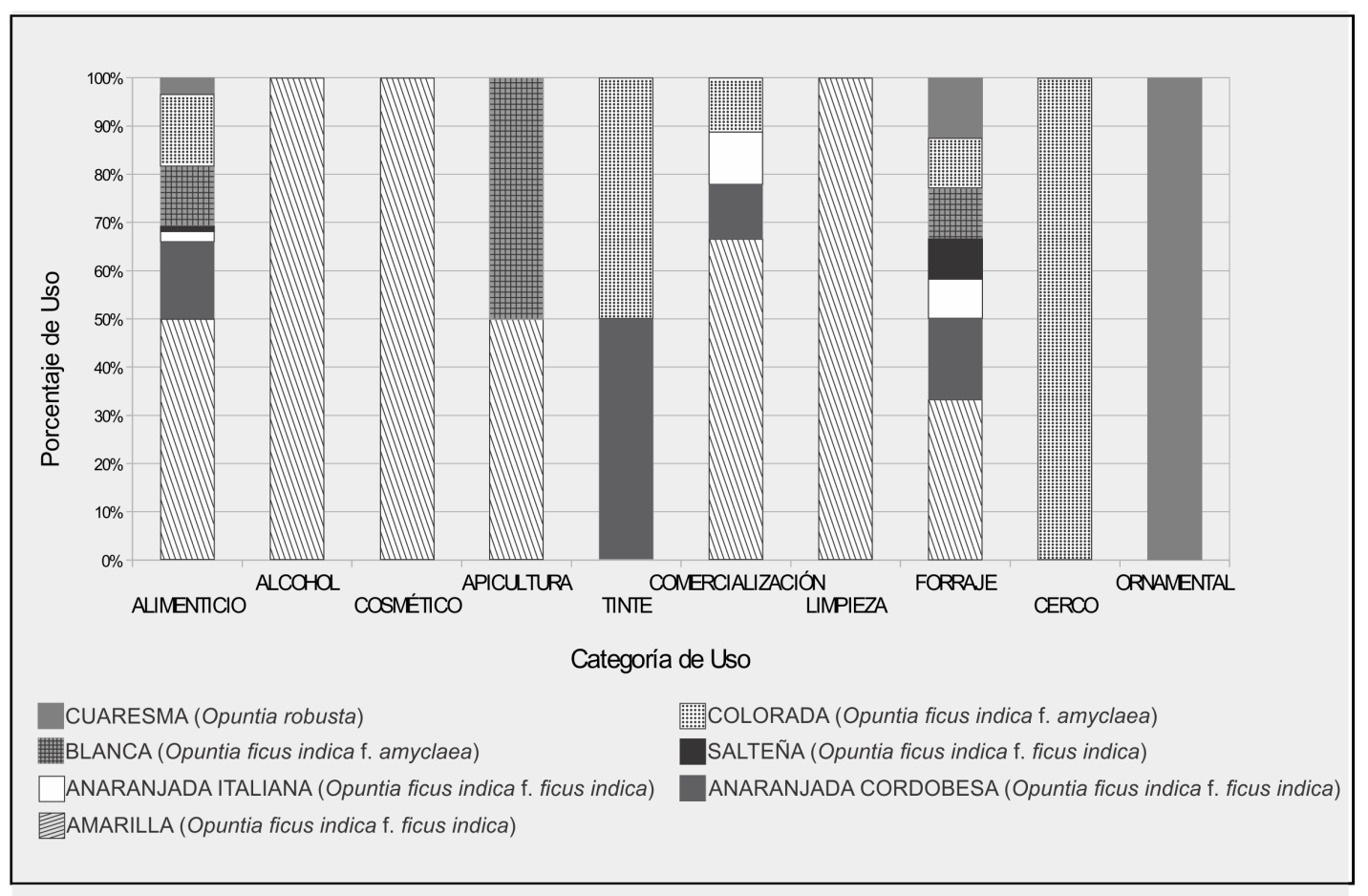

Fig. 4. Porcentaje de uso de cada etnovariedad por categoría de uso. 
Tabla 1. Listado de las especies de Opuntia registradas. Para cada una se incluyen sus nombres cientificos y vernáculos, datos sobre sus usos y los números de voucher, fecha y lugar de recolección.

\begin{tabular}{|c|c|c|c|}
\hline Familia/Nombre científico & $\begin{array}{c}\text { Nombre } \\
\text { Vernáculo }\end{array}$ & Uso & Voucher, fecha y lugar (col. C. Trillo) \\
\hline \multicolumn{4}{|l|}{ CACTACEAE } \\
\hline $\begin{array}{l}\text { Opuntia ficus indica } \\
\text { f. ficus indica }\end{array}$ & Tuna Amarilla & $\begin{array}{l}\text { Alimenticio, Alcohol, } \\
\text { Cosmético, Apicultura, } \\
\text { Comercialización, } \\
\text { Limpieza, Forraje }\end{array}$ & $\begin{array}{l}\text { ARGENTINA. Prov. Córdoba: Dpto. Río Seco, } \\
\text { Punta del Monte, 20-X-2015, Demaio, Pablo } 490 \\
\text { Trillo, Cecilia y Ahumada, Luján }\end{array}$ \\
\hline $\begin{array}{l}\text { Opuntia ficus indica } \\
\text { f. ficus indica }\end{array}$ & $\begin{array}{l}\text { Tuna Anaranjada } \\
\text { Cordobesa }\end{array}$ & $\begin{array}{l}\text { Alimenticio, Tinte, } \\
\text { Comercialización, } \\
\text { Forraje }\end{array}$ & $\begin{array}{l}\text { ARGENTINA. Prov. Córdoba: Dpto. Río Seco, } \\
\text { Punta del Monte, 20-X-2015, Demaio, Pablo } 490 \\
\text { Trillo, Cecilia y Ahumada, Luján }\end{array}$ \\
\hline $\begin{array}{l}\text { Opuntia ficus indica } \\
\text { f. ficus indica }\end{array}$ & $\begin{array}{l}\text { Tuna Anaranjada } \\
\text { Italiana }\end{array}$ & $\begin{array}{l}\text { Alimenticio, } \\
\text { Comercialización, } \\
\text { Forraje }\end{array}$ & $\begin{array}{l}\text { ARGENTINA. Prov. Córdoba: Dpto. Río Seco, } \\
\text { Punta del Monte, 20-X-2015, Demaio, Pablo } 490 \\
\text { Trillo, Cecilia y Ahumada, Luján }\end{array}$ \\
\hline $\begin{array}{l}\text { Opuntia ficus indica } \\
\text { f. ficus indica }\end{array}$ & Tuna Salteña & Alimenticio, Forraje & $\begin{array}{l}\text { ARGENTINA. Prov. Córdoba: Dpto. Río Seco, } \\
\text { Punta del Monte, 20-X-2015, Demaio, Pablo } 490 \\
\text { Trillo, Cecilia y Ahumada, Luján }\end{array}$ \\
\hline $\begin{array}{l}\text { Opuntia ficus indica } \\
\text { f. amyclaea }\end{array}$ & Tuna Blanca & $\begin{array}{l}\text { Alimenticio, } \\
\text { Apicultura, Forraje }\end{array}$ & $\begin{array}{l}\text { ARGENTINA. Prov. Córdoba: Dpto. Río Seco, } \\
\text { Punta del Monte, 20-X-2015, Demaio, Pablo } 491 \\
\text { Trillo, Cecilia y Ahumada, Luján }\end{array}$ \\
\hline $\begin{array}{l}\text { Opuntia ficus indica } \\
\text { f. amyclaea }\end{array}$ & Tuna Colorada & $\begin{array}{l}\text { Alimenticio, Tinte, } \\
\text { Comercialización, } \\
\text { Forraje, Cerco }\end{array}$ & $\begin{array}{l}\text { ARGENTINA. Prov. Córdoba: Dpto. Río Seco, } \\
\text { Punta del Monte, 20-X-2015, Demaio, Pablo } 491 \\
\text { Trillo, Cecilia y Ahumada, Luján }\end{array}$ \\
\hline Opuntia robusta & Tuna Cuaresma & $\begin{array}{l}\text { Alimenticio, Forraje, } \\
\text { Ornamental }\end{array}$ & $\begin{array}{l}\text { ARGENTINA. Prov. Córdoba: Dpto. Río Seco, } \\
\text { Punta del Monte, 20-X-2015, Demaio, Pablo } 492 \\
\text { Trillo, Cecilia y Ahumada, Luján }\end{array}$ \\
\hline
\end{tabular}

un alto contenido de azúcares y vitaminas para los animales. Las etnovariedades "Anaranjadas" y "Cuaresma" son las primeras en madurar sus frutos, luego las etnovariedades "Amarilla" y "Blanca" y por último la etnovariedad "Colorada". Cabe aclarar que el uso de la raíz para forraje fue sólo mencionado para la etnovariedad "Amarilla".

En la Figura 4 se puede observar el porcentaje de menciones de uso de cada etnovariedad por categoría de uso, lo cual nos permite comparar la intensidad de uso de cada etnovariedad a partir de las menciones recibidas. Así se observa que la etnovariedad "Amarilla" es la que presenta más categorías de uso. La causa de que dicha etnovariedad sea la más utilizada puede deberse a que se encuentra en la mayoría de los espacios domésticos, al tamaño y sabor dulce de sus frutos.

Las etnovariedades "Anaranjadas" son apreciadas por su elevada productividad, pero no presentan elevados porcentajes de uso ya que sus frutos son desabridos. Es interesante destacar que las etnovariedades "Blanca" y "Colorada" (ambas presentes en el monte), arrojan similares resultados de uso.

\section{Discusión}

Los pobladores del norte de la provincia de Córdoba, designan con el nombre "tuna" a un conjunto de especies relacionadas entre sí taxonómicamente, todas ellas del género 


\section{L. Ahumada y C. Trillo - Diversidad del género Opuntia en el norte de Córdoba}

Opuntia. A partir de las entrevistas realizadas y el reconocimiento botánico de los ejemplares en los ambientes domésticos y monte se identificó una agrobiodiversidad de 7 etnovariedades tanto cultivadas como en proceso de domesticación.

En Córdoba se registró previamente la utilización de las formas ficus indica y amyclaea, constituyendo el presente trabajo el primer registro científico $O$. robusta como integrante de la diversidad provincial. Son escasos los registros científicos de la $O$. ficus-indica f. amyclaea y carentes los de $O$. robusta, además de no encontrarse ejemplares en la colección del Museo Botánico (CORD) dependiente de la Universidad Nacional de Córdoba, por lo que este trabajo es un aporte al enriquecimiento desde el punto de vista botánico y etnobotánico para nuestra provincia. Este hecho probablemente se deba a la dificultad de herborizar los representantes de cactáceas y al escaso interés en colectar especies exóticas naturalizadas.

La presencia de la forma típica de O. ficus-indica está ampliamente registrada en la bibliografía; ya desde 1905 por Río \& Achaval, que mencionan sus usos como forrajera y comestible, y Di Lullo (1935) la cita para Santiago del Estero con similares usos; en períodos más recientes Zapata et al. (2005) sistematiza las aspectos productivos y menciona por primera vez 5 variedades para la provincia de Córdoba con frutos de diferentes colores, Biurrun et al. (2007) la menciona para La Rioja como integrante de los patios como plantas alimenticia, Trillo et al. (2010) como medicinal y Torrico Chalabe \& Trillo (2015) profundizan los aspectos etnobiológicos e identifican 6 usos y la más alta valoración como recurso por parte de los pobladores del noroeste de la provincia. Di Lullo (1946) menciona que existen para la provincia de Santiago del Estero variedades de Tuna, en base a las características de sus frutos: la tuna "perra" es de corteza roja con vetas verdes, muy semilluda y de pulpa amarilla; "la tuna castilla" es amarillenta, arenosa y más dulce que la común, no cae por efecto de la madurez, es muy espinosa ; la "tuna bola o manzana" es colorada, muy asemillada y no muy sabrosa; la "tuna común, blanca, amarilla o colorada"; y por fin la "tuna pelada", amarilla y sin espinas. Sólo con estas menciones y descripciones propuestas por Di Lullo (1946), no nos es posible establecer una correlación entre los nombres vernáculos propuestos por los informantes de este estudio y los mencionados por el folcklorista, sumado al hecho de no encontrar en su recopilación menciones de la forma amyclaea, además de confusiones en la taxonomía. De todos modos, esta diversidad de formas y colores coincide en gran medida al número de etnovariedades registradas por este trabajo, motivo que refleja el interés de los pobladores en la manipulación de las distintas etnovariedades a lo largo del tiempo, exponiendo a las etnovariedades a procesos de selección artificial. Desde una perspectiva agronómica, Herrera (2003) presenta en su cartilla técnica para plantación e implementación de tuna comercial 18 variedades o ecotipos con descripciones de forma y color, las cuales no se encuentran identificadas taxonómicamente, no fueron coleccionadas o registradas en una base de datos ni mantenidas en cultivo, lo que nos dificulta la posibilidad de analizarlas y compararlas con los resultados de este trabajo.

A diferencia de la forma anterior, la $O$. ficusindica f. amyclaea sólo es mencionada por Torrico Chalabe \& Trillo (2015) en el contexto de un estudio etnobotánico del noroeste de Córdoba con el nombre común de "tuna silvestre", "tuna del monte" y "tunilla", con uso forrajero, alimenticio y para la construcción de cercos. Aunque crece espontáneamente en algunas de las localidades visitadas, no existe bibliografía de referencia de la composición florística de los bosques Chaqueños de Córdoba donde haya sido registrada. Kiesling $(1998,2013)$ explica que la posible vía de ingreso de la forma amyclaea a los ambientes naturales se debería al hecho de que si se siembran semillas producidas por plantas de la forma típica sin espinas, luego de años, podemos observar que un porcentaje menor de la descendencia presenta espinas bien desarrolladas, lo que evidenciaría que la forma amyclaea es la forma regresiva de la Opuntia ficus indica.

Respecto a $O$. robusta no hay en Córdoba registros etnográficos ni agronómicos, solamente existe una referencia a nivel nacional, ya que fue colectada en cercanías de la capital de la provincia de Salta (Kiesling et al., 2011).

Tanto la introducción de Prunus persica y Citrus sp. (Stampella et al., 2013; Lambaré, 2016), como la de las tunas y de las plantas exóticas en general, plantean una reconstrucción del paisaje cultural, que se refleja en las especies de plantas identificadas y 
sus usos. Es así, que tanto por razones ambientales como culturales, las comunidades agrícolas locales adoptaron estas plantas para cultivarlas, seleccionando a lo largo de este proceso aquellas etnovariedades consistentes con los valores locales, así como las capaces de tolerar las condiciones en un nuevo escenario (Stampella et al., 2013). Así, estas etnovariedades son reconocidas como un factor de identidad por parte de los entrevistados, ya sea a través de símbolos institucionales tal como el escudo del Municipio de Chuña, nombres vernáculos tales como "Anaranjada Cordobesa" o "Salteña", o festividades patronales como es el caso de la localidad de Chuña, nombrada capital provincial del arrope de tuna.

Es interesante destacar que la etnovariedad "Amarilla", además de haber sido mencionada por todos los entrevistados, es utilizada por los mismos como patrón de referencia para definir al resto de las etnovariedades. Existe una amplia variedad de trabajos sobre etnoclasificación a nivel global en los cuales se contempla la existencia de ejemplares prototípicos, los cuales son utilizados como puntos de referencia generadores de categorías en las que se establecen relaciones entre los diferentes miembros que la constituyen en torno a este ejemplar prototípico (Rosch, 1978; Cifuentes Honrubia, 1992). Según Duque (2003) estos ejemplares prototípicos son los miembros más representativos de una categoría y poseen un uso práctico, ya que permiten a los sujetos diferenciar entre categorías, haciéndolas más informativas.

En este estudio la etnovariedad "Amarilla" es la que registró la mayor cantidad de usos, donde la preparación de arrope y el forraje de toda la planta son los más citados, concordando en este último aspecto con Kiesling (1998); Arenas (2003); Hernández et al. (2005) y Torrico Chalabe \& Trillo (2015). Di Lullo (1935) expresa la variedad de arropes que se preparaban en Santiago del Estero, distinguiendo entre el rubio, el negro y el arrope con casco, además de la jalea, también mencionadas por Scarpa (2012) para los criollos del oeste de la provincia de Formosa, variedades de productos que continúan aún vigentes. $O$. ficus-indica es la especie de cactus de mayor importancia económica en el mundo (Kiesling, 1998). La forma ficus-indica es entre las cactáceas una de las de mayor importancia agronómica, desarrollándose en estos últimos años cultivos más o menos extensos en Santiago del
Estero, Catamarca y Córdoba, entre otras provincias del país, tanto con la finalidad de producir fruta para consumo como para exportar, además de ser una excelente forrajera de emergencia (Lozano 2011; Torrico Chalabe \& Trillo, 2015). Sus frutos son muy apetecibles, de diversos colores (Kiesling, 1998), lo cual queda demostrado a partir de los nombres de las etnovariedades registradas, y a ello se suman sus usos medicinal, alimenticio, cosmético, limpieza, apicultura, ornamental, forraje y comercial, que le otorgan una gran importancia como recurso natural (Zapata et al., 2005; Torrico Chalabe \& Trillo, 2015).

En cuanto a los usos de la forma amyclaea para la etnovariedad Colorada se registraron usos alimenticios, tinte, comercialización, forraje y cerco ampliando el espectro de uso registrado por Torrico Chalabe \& Trillo (2015) para esta etnovariedad. Como se mencionó anteriormente, es parte de cultivos en otras partes del mundo (Pimienta Barrios et al., 1995; Callejas-Juárez et al., 2009; Torres-Ponce et al., 2015). Aunque no se encontró en este trabajo, esta forma también es utilizada como ornamental (Real, 2011; Ortiz, 2014). La construcción de cerco con cactáceas fue mencionada por Torrico Chalabe \& Trillo (2015), en asociación con la especie Stetsonia coryne (Salm-Dyck) Britton et Rose. Para la etnovariedad Blanca se registraron los usos alimenticios, para apicultura y forraje. En cuanto al uso alimenticio, se registraron menciones sobre la preparación de arrope. Di Lullo (1935) menciona que la tuna "Blanca" es utilizada para la preparación de arropes denominado dulces del campo, que los criollos producen con las frutas. Ambas etnovariedades son encontradas en el monte, tal como los informantes mencionan "la Colorada está en el monte, "si usted quiere comer los frutos, va y los busca", "La Blanca hay que salir a buscarla al monte, no está en todos lados".

A esta forma amyclaea se la encuentra con frecuencia en Catamarca, Chaco, Córdoba, Formosa, La Rioja, Salta y Santiago del Estero, asilvestrada cerca de caminos o poblaciones. También se cultiva para la cría de la cochinilla de la grana y para aprovechamiento de sus frutos (Lozano, 2011).

Por otro lado, para la etnovariedad "Cuaresma", correspondiente a la especie O.robusta, se registraron usos alimenticios, de forraje, ornamental y de tinte. 


\section{L. Ahumada y C. Trillo - Diversidad del género Opuntia en el norte de Córdoba}

Existen trabajos agronómicos y etnobotánicos que concuerdan con estos usos encontrados, en los cuales se revela la utilización de ésta como forraje y ornamental en Australia (Baker et al., 2008), ornamental en España (Ortiz \& Van Der Meer, 2007), es una de las principales especies cultivadas por sus grandes frutos y para forraje en México (Pimienta Barrios et al., 1995, Ramírez Vallejo et al., 2000), con fines ornamentales en el mismo país (Griffith, 2004), y es utilizada por campesinos mayas con fines medicinales (Chan Quijano et al., 2013).

Mediante este estudio se puede observar los múltiples usos que realizan los pobladores de los recursos naturales, obteniendo una variedad de productos para complementar sus necesidades de subsistencia. Concordando con Parra et al. (2012) los sistemas agroforestales tradicionales resultan particularmente relevantes, ya que involucran componentes de la vegetación manejados a través de prácticas de domesticación. Estos sistemas abarcan una gran diversidad de sistemas productivos, entre ellos los huertos y jardines, así como los paisajes circundantes, los cuales son reconocidos por su alta capacidad de conservación de la biodiversidad natural y la agrobiodiversidad, al mismo tiempo que son dinámicos e involucran sistemas socioecológicos, los cuales son mantenidos mediante estrategias de manejo generadoras de diversidad biológica.

Estudiar la domesticación, intentando aproximarse no sólo al nivel de poblaciones biológicas, sino también a nivel de percepción de paisaje -en este caso, doméstico y monte-, podría acercarnos a un mayor entendimiento de los procesos de interacción que ocurren tanto a nivel de sistemas agrícolas como no-agrícolas. Además, en concordancia con Lambaré (2016), acercarse a través de la metodología etnobotánica al estudio de la domesticación de una especie vegetal, registrando las prácticas de manejo sobre el mismo, ha demostrado ser muy valioso en la interpretación de prácticas de cultivo en el pasado y su vínculo con la domesticación de especies vegetales, y tal como sostienen Zamudio \& Hilgert (2012) esta información puede ser utilizada por los educadores de la zona de estudio, ya que contienen información biológica y cultural desprendida del conocimiento local, reflejo de la identidad social de estos pobladores.

\section{Conclusiones}

Los pobladores del norte de la provincia de Córdoba agrupan y designan con el nombre "tuna" a un conjunto de especies relacionadas entre sí taxonómicamente, actualmente cultivadas y en proceso de domesticación en las localidades estudiadas, de las cuales 6 corresponde a la especie botánica $O$. ficus-indica (4 a la forma típica ("Amarilla común", "Anaranjada Cordobesa", "Anaranjada Italiana" y "Salteña") y dos a la forma amyclaea ("Colorada" y "Blanca") y una a la especie O. robusta ("Cuaresma").

Se registraron 10 categorías de uso diferentes para todas las etnovariedades, siendo las más importantes la categoría alimenticia, forraje y la comercialización de productos derivados de los frutos.

\section{Agradecimientos}

A los pobladores entrevistados que permitieron la realización de este trabajo, en especial a Mistol y Corina. A Daniel Herrera por su colaboración en cuanto a la identificación de informantes. Al Dr. Pablo Demaio por su colaboración en la identificación de las especies estudiadas. A SECYT por la financiación del proyecto "Percepción, manejo y uso de unidades de paisaje en la zonas rurales de Córdoba" 37126/2014.

\section{Bibliografía}

AGUILERA, R. M., A. DURAND-SMITH, E. M. RODRÍGUEZ \& M. ROMERO MENDOZA. 2003. Veinticinco años de investigación cualitativa en salud mental y adicciones con poblaciones ocultas. Primera parte. Salud Mental 26: 76-83.

AGUiRRE-DEGUÁ, X., L. E. EGUIARTE, A. GONZALES-RODRÍGUEZ \& A. CASAS. 2012.

Round and large: morphological and genetic consequences of artificial selection on the gourd tree Crescentia cujete by the Maya of the Yucatan Peninsula, Mexico. Annals of Botany 109: 12971306.

ALDRIGE, A. \& K. LAVINE. 2003. Topografía del mundo social. Teoría y práctica de la investigación mediante encuestas. Gedisa Editorial, España.

ARENAS, P. 2003. Etnografia y alimentación enre los Toba-Ñachilamole\#tek y Wichi-Lhuku'tas del 
Chaco Central (Argentina). Argentina Latin Gráfica, Buenos Aires, Argentina.

BAKER, J., M. KELLER \& C. PRESTON. 2008. Genetic variability of wheel cactus (Opuntia robusta Wendl.) in southern Australia: implications for weed spread and biological control. Proceedings of the 16th Australian Weeds Conference: 18-22.

BELLÓN, M. R., A. F. BARRIENTOS-PRIEGO, P. COLUNGA-GARCÍA MARÍN, H. PERALES, J. A. REYES-AGÜERO, R. ROSALES-SERNA \& D. ZIZUMBO-VILLAREAL. 2009. Diversidad y conservación de recursos genéticos en plantas cultivadas. Capital natural de México 2: 355-382.

BERLIN, B. 1992. Ethnobiological Classification: principles of categorization of plant and animals in traditional societies. 1st ed. Princeton University Press, Princepton, New Jersey.

BERNARD, H. R. 1994. Research Methods in Anthropology Qualitative and Quantitative Approaches, 2nd ed. Altamira Press, UEA.

BIURRUN, E., L. GALETTO, A. M. ANTON \& F. BIURRUN. 2007. Plantas silvestres comestibles utilizadas en poblaciones rurales de la Provincia de La Rioja (Argentina). Kurtziana 33: 121-140.

BRAVO H. H. \& H. SÁNCHEZ-MEJORADA. 1978. Las cactáceas de México, 2nd ed., pp. 324-333. Universidad Nacional Autónoma de México. DF, México.

BRITTON, N. L. \& J. N. ROSE. 1919. The Cactaceae, 4. Carnegie Institution, Washington DC.

CABIDO, M. \& M. ZAK. 1999. Vegetación del Norte de Córdoba. Secretaría de Agricultura, Ganadería y Recursos Renovables de la provincia de Córdoba y Agencia Córdoba Ambiente, Córdoba.

CABIDO, M., M. R. ZAK, A. CINGOLANI, D. CÁCERES \& S. DÍAZ. 2005. Cambios en la cobertura de la vegetación del centro de Argentina. ¿Factores directos o causas subyacentes? En: OESTERHELD, M.; M. AGUIAR, C. GHERSA \& J. PARUELO (Eds.). La heterogeneidad de la vegetación de los agroecosistemas, pp. 271-300. Universidad Nacional de Buenos Aires, Buenos Aires.

CABRERA, A. L. 1976. Regiones fitogeográficas argentinas. Enciclopedia Argentina de Agricultura y Jardinería, 2nd ed. Argentina.

CALLEJAS-JUÁREZ, N., J. A. MATUS-GARDEA, J. A. GARCÍA-SALAZAR, M. A. MARTÍNEZDAMIÁN \& J. M SALAS-GONZÁLEZ. 2009. Situación actual y perspectivas de mercado para la tuna, el nopalito y derivados en el Estado de México, 2006. Agrociencia 43: 73-82.

CASAS, A. 2001. Silvicultura y Domesticación de plantas en Mesoamérica. En: RENDÓN AGUILAR, B.; S. REBOLLAR DOMÍNGUEZ, S.; J. CABALLERO
NIETO, \& M. A. MARTÍNEZ ALFARO (Eds.) Plantas, Cultura y Sociedad. Estudio sobre la relación entre seres humanos y plantas en los albores del siglo XXI, 1ra ed, pp. 123-157 .Universidad Autónoma de México. DF, México.

CASAS, A., A. CAMOU, A. OTERO-ARNAIZ, S. RANGEL-LANDA, J. CRUSE-SANDERS, L. SOLIS, I. TORRES, A. DELGADO, A. I. MORENO- CALLES, M. VALLEJO, S. GUILLÉN, J. BLANCAS, F. PARRA, B. FARFÁN-HEREDIA, X. AGUIRRE-DUGUA, Y. ARELLANES \& E. PÉREZ-NEGRÓN. 2015. Manejo tradicional de biodiversidad y ecosistemas en Mesoamérica: el Valle de Tehuacán. Investigación ambiental Ciencia y política pública $6: 23-44$.

CHAN-QUIJANO, J. G., M. K. PAT-CANCHÉ \& J. SARAGOS-MÉNDEZ. 2013. Conocimiento etnobotánico de las plantas utilizadas en Chancah Veracruz, Quintana Roo, México. Teoría y Praxis 14: 9-24.

CIFUENTES HONRUBIA, J. L. 1992. Teoría de prototipos y funcionalidad semántica. ELUA Estudios de Lingüística 8: 133-177.

COSTA-NETO, E. M. 2002. Manual de Etnoentomología, 4: 77-87. Sociedad Entomológica Aragonesa. Zaragoza, España.

COTTON, C. M. 1996. Ethnobotany: principles and applications. Edit John Wiley \& Sons.

DEMAIO, P. \& M. TREVISSON. 2006. Cactus de Córdoba y el centro de Argentina. 1ra ed. L.O.L.A., Buenos Aires, Argentina.

DI LULLO, O. 1935. La alimentación popular de Santiago del Estero. Franco Rossi. Buenos Aires, Argentina.

DI LULlO, O. 1946. Contribución al estudio de las voces santiagueñas. Franco Rossi. Buenos Aires, Argentina.

DUQUE, P. H. 2003. Teoria dos protótipos, categoria e sentido lexical [online]. Disponible en: http://www. filologia.org.br/revista/artigo/7(21)13.htm .[Acceso: 15 September 2016].

FALASCA, S., M. A. BERNABÉ \& C. LAMAS. 2011. Aptitud agroclimática de áreas áridas y semiáridas de Argentina para el cultivo de tuna (Opuntia ficus indica) como fuente de bioetanol. Quebracho (Santiago del Estero) 19: 66-74.

GRIFFITH, M. P. 2004. The origins of an important cactus crop, Opuntia ficus-indica (Cactaceae): new molecular evidence. Am. J. Bot. 91: 1915-1921.

HERNÁNDEZ, H. M., J. A. REYES-AGÜERO \& J. R. AGUIRRE-RIVERA. 2005. Systematic notes and a detailed description of Opuntia ficus-indica (L.) Mill. (Cactaceae). Agrociencia 39: 395-408.

HERRERA, D. 2003. Tuna: Planificación e implantación del tunal comercial, 1ra ed. INTA, Oficina Técnica 


\section{L. Ahumada y C. Trillo - Diversidad del género Opuntia en el norte de Córdoba}

Villa María, EEA Manfredi. Villa de María del Río .Seco, Córdoba, Argentina

HURRELL, J. 2014. Urban Ethnobotany in Argentina: Theoretical advances and methodological strategies. Ethnobio Conserv 3: 1-11

KARLIN, M., R. COIRINI, R. ZAPATA \& A. CONTRERAS. 2010. Manejo sustentable del ecosistema Salinas Grandes, Chaco árido, 1ra ed. Encuentro Grupo Editor, Córdoba, Argenitna.

KIESLING, R. 1998. Origen, domesticación y distribución de Opuntia ficus-indica. J. Prof. Assoc. Cactus 3: 5059.

KIESLING, R. 2013. Historia de la Opuntia ficusindica. Cactus Newsletter. Special Issue 13.

KIESLING, R. \& O. E. FERRARI. 2005. 100 cactus Argentinos. Editorial Albatros Saci. Buenos Aires, Argentina.

KIESLING, R., M. SARAVIA, L. OAKLEY, N. MURUAGA, D. METZING, L. NOVARA. 2012. Cactaceae Juss. Flora el Valle de Lerma. Aportes Botánicos de Salta - Ser. Flora 10: 30-31. Herbario MCNS. Facultad de Ciencias Naturales de Salta. Salta, Argentina.

KRAPOVICKAS, A. 2010. La domesticación y el origen de la agricultura. Bonplandia 19: 193-199.

LAMBARÉ, D. A. 2016. Manejo de variedades locales de Prunus persica (Rosaceae) en la Quebrada de Humahuaca, Argentina y su relación con los sistemas agrícolas tradicionales. Zonas Áridas 15: 128-147.

LÓPEZ-GUTIÉRREZ, D. M., J. A. REYES-AGÜERO, A. MUÑOZ, J. ROBLES \& E. CUEVAS. 2015. Comparación morfológica entre poblaciones silvestres y manejadas de Opuntia atropes (Cactaceae) en Michoacán, México. Revista Mexicana de Biodiversidad 86: 1072-1077.

LOPEZ PINERO, J. M., J. L. FRESQUET FEBRER, M. L. LOPEZ TERRADA \& J. PARDO TOMAS. 1992. Medicinas, drogas y alimentos vegetales del Nuevo Mundo. Textos e imágenes españolas que los introdujeron en España. Madrid, Ministerio de Sanidad y Consumo.

LOZANO, L. 2011. Ecofisiología de la tuna (Opuntia ficus-indica (L.) Mill.). Horticultura Argentina 30: 37-52. Universidad Nacional de Salta.

MAJURE, L. C., R. PUENTE, M. P. GRIFFITH, W. S. JUDD, P. S.SOLTIS \& D. E. SOLTIS. 2012. Phylogeny of Opuntia s.s. (Cactaceae): clade delineation, geographic origins, and reticulate evolution. Am. J. Bot. 99: 847-864.

MANZANAL, M. \& A. B. ROFMAN. 1989. Las economías regionales de la Argentina: crisis y políticas de desarrollo. 1ra ed. Centro Editor de América Latina, Argentina.

MORELLO, J. H., A. F. RODRIGUEZ \& W. PENGUE. 2009. El Chaco sin Bosques: la Pampa o el desierto del futuro. Orientación Gráfica Editores, Buenos Aires.

MUÑOZ URIAS, A., G. PALOMINO-HASBACH, T. TERRAZAS, A. GARCÍA-VELÁZQUEZ \& E. PIMIENTA-BARRIOS. 2008. Variación anatómica y morfológica en especies y entre poblaciones de Opuntia en la porción sur del Desierto Chihuahuense. Bol. Soc. Bot. Méx. 83: 1-11.

OBÓN, C. \& D. RIVERA. 2005. Origen y conservación de las plantas cultivadas: la agrobiodiversidad en la cuenca del río Segura (España). Recursos Rurais 1: 51-59.

ORTIZ, D. G. 2014. Apuntes para una flora ornamental de la provincia de Castellón (España). Bouteloua 19: $178-186$.

ORTIZ, D. G. \& P. VAN DER MEER. 2007. Un nuevo taxon alóctono naturalizado en Cataluña: Opuntia robusta Wendland. Stud. Bot. 26: 121-124.

PADUA, J. 1994. Técnicas de investigación aplicadas a las ciencias sociales. Fondo de Cultura Económica Chile S. A.

PARRA, F., J. J. BLANCAS \& A. CASAS. 2012. Landscape management and domestication of Stenocereus pruinosus (Cactaceae) in the Tehuacán Valley: human guided selection and gene flow. $J$ Ethnobiol Ehnomed 8: 1-17.

PERALES, H., S. B. BRUSH \& C. O. QUALSET. 2003. Dynamic management of maize landraces in central Mexico. Econ. Bot. 57: 21-34.

PIMIENTA-BARRIOS, E., S. L. CORNEJO \& M. G. E. DELCASTILLO-ARANDA. 2003. Caracterización anatómica y conductividad hidráulica teórica de los elementos de vaso de variedades silvestres y cultivadas de nopal tunero (Opuntia). Acta Bot. Mex. 62: 21-30.

PIMIENTABARRIOS, E., M.A. URIAS, G. BARBERA, P. INGLESE, E. PIMIENTA BARRIOS \& A. JIMENEZ. 1995. Domestication of opuntias and cultivated varieties. Agro-ecology cultivation and uses of cactus pear. FAO, Roma (Italia).

POCHETTINO, M. L., J. A. HURRELL, V. S. LEMA. 2012. Local botanical knowledge and agrobiodiversity: homegardens at rural and periurban contexts in Argentina. In: LUNA MALDONADO, A. I. (Ed.), Horticulture, pp. $105-$ 132. Tech, Rijeka.

RAMÍREZ VALLEJO, A., R. P. ORTEGA, A. H. LÓPEZ, F. G. CASTILlO, M. M. LIVERA, F. S. RINCÓN \& F. G. ZAVALA. 2000. Recursos Fitogenéticos de México para la Alimentación y la Agricultura, Informe Nacional. Servicio Nacional de Inspección y Certificación de Semillas y Sociedad Mexicana. Chapingo, México.

REAL, D. S. F. 2011. Propagación in vitro de cultivares de tuna. Bol. Soc. Latin. Carib. Cact. Suc. 8: 14-18. 
REYES-AGÜERO, J. A. \& A. VALIENTE-BANUET. 2006. Reproductive biology of Opuntia: a review. $J$. Arid Enviro 64(4): 549-585.

RÍO, M \& L. ACHÁVAL. 1905. Geografía de la provincia de Córdoba. Compañía Sudamericana de Billetes de Bancos. Buenos Aires, Argentina.

RODRÍGUEZ, P. E. 2004. Los frutos de las Cactáceas y su potencial como materia prima. Agronomía mesoamericana 15: 215-219.

ROSCH, E. 1978. Principies of Categorization. In: ROSCH E. \& B. LOYD (Eds.) Cognition and Categorization, pp 27-48. Laurence Erlbaum Ass, Hilldale, New Jersey.

SCARPA, G. F. 2012. Las plantas en la vida de los criollos del oeste formoseño: medicina, ganadería, alimentación y viviendas tradicionales, 1 ra ed. Asociación Civil Rumbo Sur. Buenos Aires, Argentina.

STAMPELLA, P. C., D. A. LAMBARÉ, N. I. HILGERT \& M. L. POCHETTINO. 2013. What the Iberian Conquest Bequeathed to Us: The Fruit Trees Introduced inArgentine Subtropic - TheirHistory and Importance in Present Traditional Medicine. eCAM 2013: 1-17. doi:10.1155/2013/868394

TORRES-PONCE, R. L., D. MORALES-CORRAL, M. DE LOURDES BALLINAS-CASARRUBIAS \& G. V. NEVÁREZ-MOORILLÓN. 2015. El nopal: planta del semidesierto con aplicaciones en farmacia, alimentos y nutrición animal. Revista Mexicana de Ciencias Agrícolas 6: 1129-1142.

TORRICO CHALABE, J. \& C. TRILLO. 2015. Prácticas de manejo, usos y valoración de taxones de Cactaceae en el Noroeste de Córdoba, Argentina. Bonplandia 24: 5-22.
TRILLO, C. 2010. Valoración del bosque y conocimiento de las plantas silvestres por parte de los pobladores de las Sierras de Guasapampa, Noroeste de la Provincia de Córdoba. Tesis Doctoral, Hemeroteca de la FCEFyN UNC.

TRILLO, C., B. ARIAS TOLEDO, L. GALETTO \& S. COLANTONIO. 2010. Persistence of the Use of Medical Plants in Rural Comunities of the Western Arid Chaco [Córdoba, Argentina]. The Open Complementary Medicine Journal 2: 80-89.

TRILlO, C., S. COLANTONIO \& L. GALETTO. 2014. Perceptions and Use of Native Forests in the Arid Chaco of Córdoba, Argentina. Ethnobotany Research and Application 12: 497-510.

ZAMUDIO, F. \& N. I. HILGERT. 2012. Descriptive attributes used in the characterization of stingless bees (Apidae: Meliponini) in rural populations of the Atlantic forest (Misiones-Argentina). J Ethnobiol Ehnomed 8: 1-10.

ZAPATA, R. M., U. O. KARLIN, F. LUCERO, R. O. COIRINI \& M. KARLIN. 2005. Manejo Sustentable del Ecosistema Salinas Grandes. Manejo de los tunales. Proyecto "Desarrollo de un polo productivo integral en el norte de Córdoba: cultivo y procesamiento de la tuna (Opuntia ficus-indica) $y$ especies aromáticas bajo certificación orgánica". Proyectos Federales de Innovación Productiva del Ministerio de Ciencia, Tecnología e Innovación Productiva. Cartilla $N^{\circ} 2$. Altric.

Recibido 16 de Junio de 2016, aceptado 30 de agosto de 2016. 